\title{
A New Dual Band Printed Metamaterial Antenna for RFID
} Reader Applications

\author{
Abdelhadi Ennajih ${ }^{1}$, Jamal Zbitou ${ }^{2}$, Mohamed Latrach ${ }^{3}$, Ahmed Errkik $^{4}$, Rachid Mandry ${ }^{5}$ \\ ${ }_{1,2,4,5}$ LMEET FST of Settat, Hassan 1st University, Settat, Morocco \\ ${ }^{3}$ Microwave Group (ESEO), Angers, France
}

\begin{tabular}{|c|c|}
\hline Article Info & ABSTRACT \\
\hline Article history: & In this paper, we present a new dual band metamaterial printed antenna for \\
\hline Received Feb 12, 2017 & $\begin{array}{l}\text { radio frequency identification applications. The proposed antenna consists of } \\
\text { two L-shaped slot in the radiating element for dual band operation and a }\end{array}$ \\
\hline Revised Jun 23, 2017 & complementary split ring resonator etched from the ground plane for size \\
\hline Accepted Aug 5, 2017 & miniaturization. This antenna is designed and optimized by CST microwave \\
\hline Keyword: & $\begin{array}{l}\text { and tangent loss of } 0.025 \text {. A microstrip line with characteristic impedance of } \\
50 \mathrm{ohms} \text { is used to feed this antenna. A prototype of the proposed antenna is }\end{array}$ \\
\hline CSRR & fabricated to validate the simulation results. The measured and simulated \\
\hline Metamaterial & results are in good agreement. \\
\hline Microstrip antenna & \\
\hline RFID & \\
\hline & $\begin{array}{r}\text { Copyright (C) } 2017 \text { Institute of Advanced Engineering and Science. } \\
\text { All rights reserved. }\end{array}$ \\
\hline \multicolumn{2}{|l|}{ Corresponding Author: } \\
\hline \multicolumn{2}{|l|}{ Abdelhadi Ennajih, } \\
\hline \multicolumn{2}{|c|}{ LMEET FST of Settat, } \\
\hline \multicolumn{2}{|c|}{ Hassan 1st University, Settat, Morocco. } \\
\hline \multicolumn{2}{|c|}{ BP : 577, Route de Casablanca -, Settat, Maroc. } \\
\hline \multicolumn{2}{|c|}{ Email: abdelhadi.ennajih@gmail.com } \\
\hline
\end{tabular}

\section{INTRODUCTION}

RFID stands for Radio frequency identification. It is a generic term used to describe a technology that uses radio waves for the purposes of identification and tracking tags attached to an object, animal or person. Nowadays, RFID technology has been popular and widely adopted for various applications such as access control, supply chain management, file tracking, race timing, animal farms, smart labels, library, security, healthcare, sports, and other areas [1, 2, 3, 4]. Generally, an RFID system consists of three basic components: a transponder, a reader and a controller [5]. The reader or interrogator is a simple device that is composed of an antenna, an RF electronics module, and a control electronic module, the reader is used to read and write information from the tag. The transponder or tag is composed of a semiconductor chip, an antenna and sometimes a battery, the transponder provides information about the tagged object. The controller most often takes the form of a PC, or a workstation running database and control software.

There are several different frequencies for RFID system, which can be used. Generally, there is the low-frequency band (from $125 \mathrm{KHz}$ to $134 \mathrm{KHz}$ ), the high-frequency band $(13.56 \mathrm{MHz}$ ), the ultra-high frequency band (from $860 \mathrm{MHz}$ to $960 \mathrm{MHz}$ ) and the microwaves frequency band $(2.45 \mathrm{GHz}$ or $5.8 \mathrm{GHz}$ ) [6]. The microwaves frequency bands are popular than other RFID bands in many areas because of their high readable range, fast reading speed, large information storage capability and low cost. In 1968, the Russian physicist Victor G. Veselago has introduced an artificial material which has a negative permeability and permittivity values and this material is called metamaterial [7]. Metamaterial structure consists of thin wire elements to generate negative permittivity and Split Ring Resonators (SRRs) to produce negative permeability. 
The electromagnetic properties of the split ring resonators have been already analyzed in [8, 9], this analysis shows that SRRs structures behave as an LC resonator that can be excited by an external magnetic flux. The topologies of the SRR and its equivalent circuit model are shown in Figure 1(a) [10]. Figure1(b) represents the complementary split ring resonator (CSRR) which is the negative image of the SRR structure and it is the constative element for the synthesis of negative permittivity [11]. Where $C_{0}$ indicates the total capacitance between the rings and $C_{s}$ is the series capacitance of upper and lower halves of the SRR, that is $C_{s}=C_{0} / 4$, and $L_{s}$ can be approximated by a single ring with radius " $r_{0}$ " and width "c" [6].
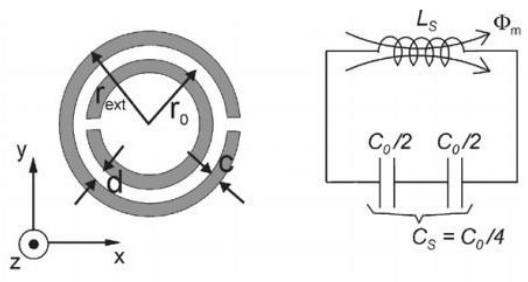

a
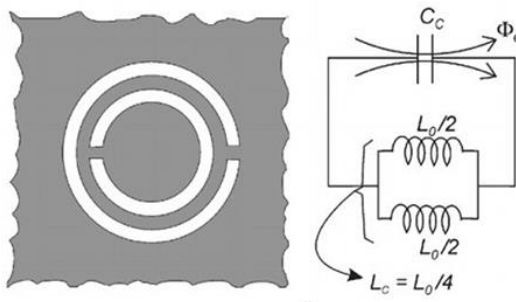

$\mathrm{b}$

Figure 1. Topology and equivalent circuit modelof (a) SRR (b) CSRR

In this paper, we present a dual band printed metamaterial antenna for RFID reader applications. A complementary split ring resonator (CSRR) is used in the ground plane for size miniaturization. By adjusting the size of the CSRR we can easily achieve good performances in term of gain, return loss and bandwidth.

\section{ANTENNA DESIGN}

\subsection{Performance Criteria}

The big challenge of an RFID system is the maximum distance at which the RFID reader can detect the backscattered signal from the transponder. The read range can be affected by a number of parameters such as, the gain and the frequency. The read range R can be computed by using the Friss equation [12]:

$$
R=\frac{\lambda}{4 \pi} \sqrt{\frac{P_{t} G_{t} G_{r} \tau}{P_{t h}}}
$$

Where $\lambda$ is the wavelength, $P_{t}$ is the power transmitted by the reader, $G_{t}$ is the gain of the reader antenna, $G_{r}$ is the gain of the transponder antenna, $\tau$ is the power transmission coefficient and $P_{t h}$ is the minimum power threshold to activate the tag chip. The reading distance is related to the gain of the reader antenna and the gain of the transponder antenna. The gain is related to the antenna size, the bigger the antenna, the greater the range. The development of the RFID technology demand antenna with small size. However, antenna with small size and high gain is hard to achieve. To eliminate these limitations, we used a metamaterial unit cell in the ground plane of the proposed antenna and the procedure design is presented in the second part of this section.

\subsection{Design Procedure}

The proposed antenna is designed on FR4 epoxy substrate with thickness of $\mathrm{h}=1.6 \mathrm{~mm}$, dielectric constant $\varepsilon_{r}=4.4$, loss tangent $\tan (\delta)=0.025$ and the thickness of copper $\mathrm{t}=0.035 \mathrm{~mm}$. The antenna geometry consists of a rectangular patch with two unequal sized L-shaped slot in the radiation element. Microstrip line feed has a characteristic impedance of $50 \mathrm{ohms}$ is used for feeding the antenna. The proposed antenna has a compact size of $40 \mathrm{~mm}$ x $30 \mathrm{~mm}$, Figure 2 shows the geometrical parameters of the antenna and its dimensions are shown in Table 1. 


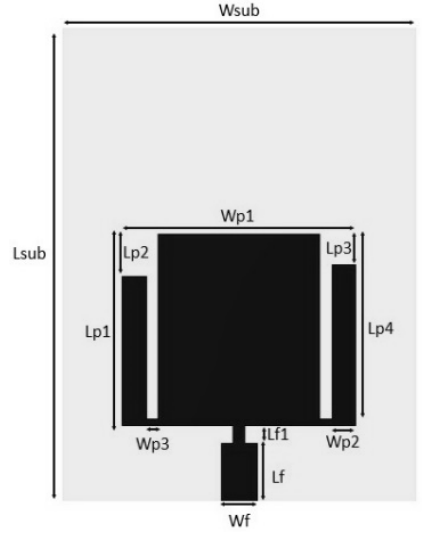

Figure 2. Geometry of the proposed antenna

Table 1. Optimized parameters of the proposed antenna

\begin{tabular}{cccc}
\hline Parameter & $\begin{array}{c}\text { Dimension } \\
(\mathrm{mm})\end{array}$ & Parameter & $\begin{array}{c}\text { Dimension } \\
(\mathrm{mm})\end{array}$ \\
\hline Lsub & 40 & Lp3 & 3.5 \\
Wsub & 30 & Wp3 & 1 \\
Lp1 & 16 & Lp4 & 15.5 \\
Wp1 & 19.6 & Wf & 3 \\
Lp2 & 2.5 & Lf1 & 1.5 \\
Wp2 & 2 & Wf1 & 1 \\
\hline
\end{tabular}

In order to obtain multiple resonant frequencies and size miniaturization, a complementary split ring resonators (CSRR) was etched from the ground plane under the radiating patch. The desired resonant frequencies achieved by adjusting the dimensions of the CSRR, the width, the length between the rings and the gap. In addition, by varying the geometry of the L-shaped slot, we can easily achieve good performances in term of bandwidth, gain and return loss. The antenna shape and its dimensions were simulated and optimized by using the Electromagnetic solver CST Microwave Studio. The geometry of the CSRR is presented in Figure 3 and the proposed antenna is illustrated in Figure 4. The optimized parameters of the complementary split ring resonator are as follows: $\mathrm{Wr}=23.5 \mathrm{~mm}, \mathrm{Ws}=0.6 \mathrm{~mm}, \mathrm{Ws} 1=20 \mathrm{~mm}, \mathrm{~g}=1 \mathrm{~mm}$ and $\mathrm{g} 1=1 \mathrm{~mm}$.

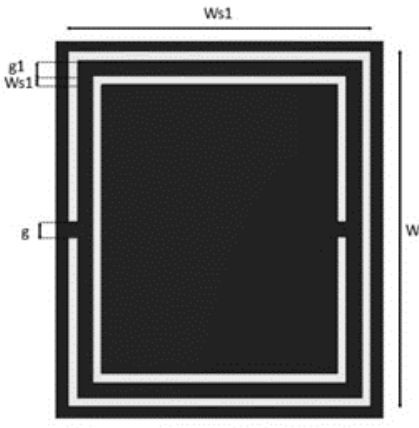

Figure 3. The metamaterial unit cell at the ground plane of the proposed antenna

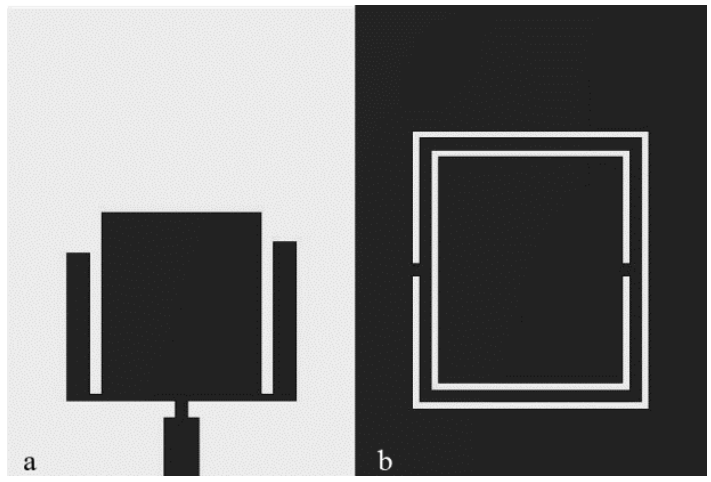

Figure 4. The proposed antenna, (a) Front view, (b) Back view

After many simulations of the proposed antenna by using optimization method in CST Microwave studio, we conclude that every parameter has different effect on the performance of the antenna. The effect of the length, the width and the gap between the rings of the CSRR are investigated. Figure 5 illustrates the simulated return loss S11 versus frequency of the proposed antenna for different lengths of Lp3. It can be observed that by increasing the length of $\mathrm{Lp} 3$ from $1 \mathrm{~mm}$ to $7 \mathrm{~mm}$ the upper and the lower resonant frequency decrease. The optimized value is achieved at $\mathrm{Lp} 3=3.5 \mathrm{~mm}$. The Simulated return loss S11 versus frequency is presented in Figure 6 for different heights of Lp4 from $8 \mathrm{~mm}$ to $15.5 \mathrm{~mm}$, all parameters are 
kept constant. By increasing the lengths of Lp4, the first resonant frequency decreases and the second frequency remains unchanged. The optimized value of Lp4 $=15.5 \mathrm{~mm}$.

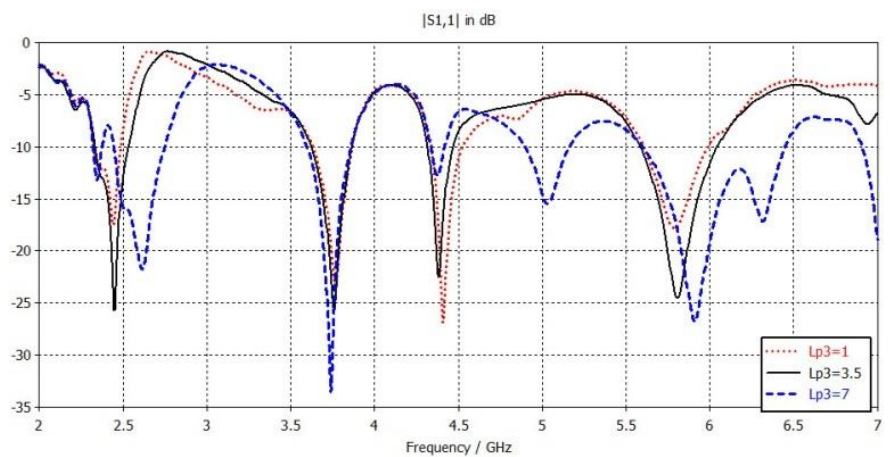

Figure 5. Return loss of proposed antenna for different values of Lp3

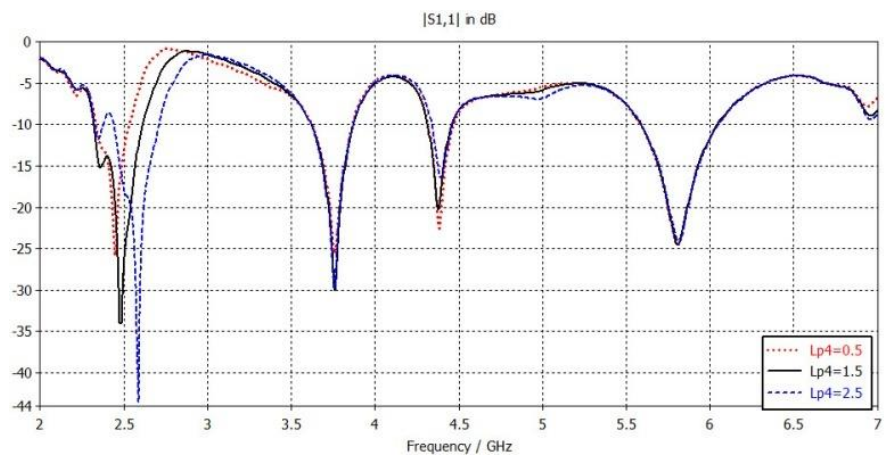

Figure 6. Return loss of proposed antenna for different values of Lp4

Figure 7 shows the simulated return loss versus frequency for different values of the length of the CSRR structure. As the length Ws of the CSRR decreases from $1.2 \mathrm{~mm}$ to $0.6 \mathrm{~mm}$, the resonant frequencies are moved to a lower value, the optimized value of Ws is $0.6 \mathrm{~mm}$.

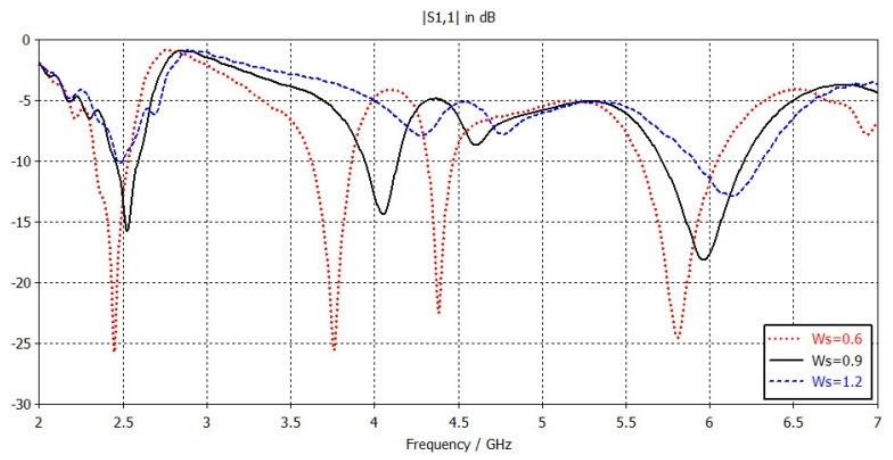

Figure 7. Return loss of proposed antenna for different values of Ws

After optimization, we have validated the final antenna geometry. Figure 8 presents the simulated return loss against frequency of the final circuit.As shown in the figure, the antenna operates at two RFID frequency bands $2.45 \mathrm{GHz}$ and $5.8 \mathrm{GHz}$ with return loss of $-25.73 \mathrm{~dB}$ at the first RFID frequency band and below $-24.47 \mathrm{~dB}$ at the second RFID frequency band. The impedance bandwidth of the proposed antenna is 
from $2.33 \mathrm{GHz}$ to $2.53 \mathrm{GHz}$ for the first resonant frequency and from $5.58 \mathrm{GHz}$ to $6.04 \mathrm{GHz}$ for the second resonant frequency band. In order to compare the simulation results obtained by using CST Microwave Studio based on the finite integration technique (FIT), we have made another simulation using HFSS based on the finite element method (FEM). The simulated results are shown in Figure 9. As we can see, the obtained results are nearly the same. The slight difference is due to the two different numerical methods employed.

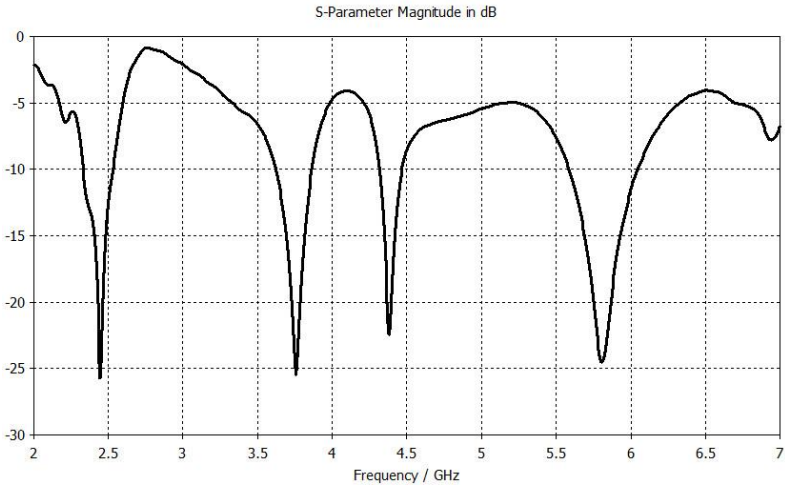

Figure 8 . The return loss vs. frequency of the proposed antenna

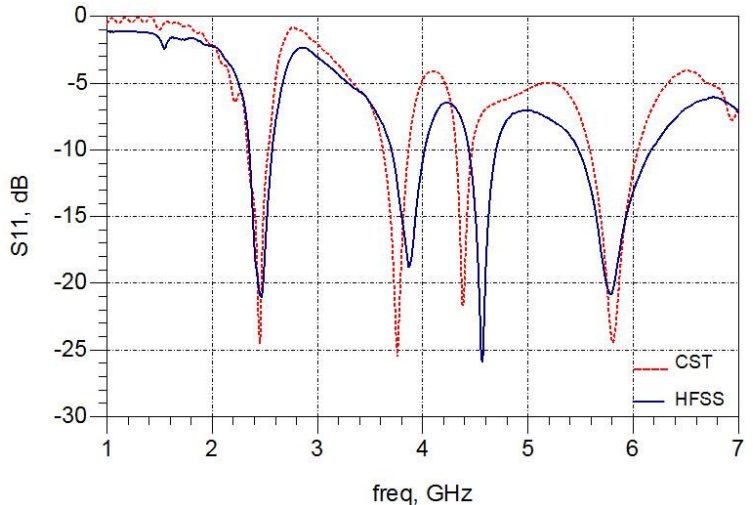

Figure 9. Comparison return loss between CST and HFSS of the proposed antenna

The peak gain of the antenna is $1.85 \mathrm{~dB}$ for the first frequency band and $3.92 \mathrm{~dB}$ for the second frequency band, Figure 10 presents the computed gain results versus frequency. The simulated radiation patterns of the proposed antenna at 2.45 and $5.8 \mathrm{GHz}$ in $\mathrm{H}$-plane and E-plane are illustrated in Figure 11 and Figure 12 respectively. As can be seen in Figure 11, the proposed antenna has a bidirectional radiation pattern at $2.45 \mathrm{GHz}$ in both $\mathrm{H}$-plane and E-plane.

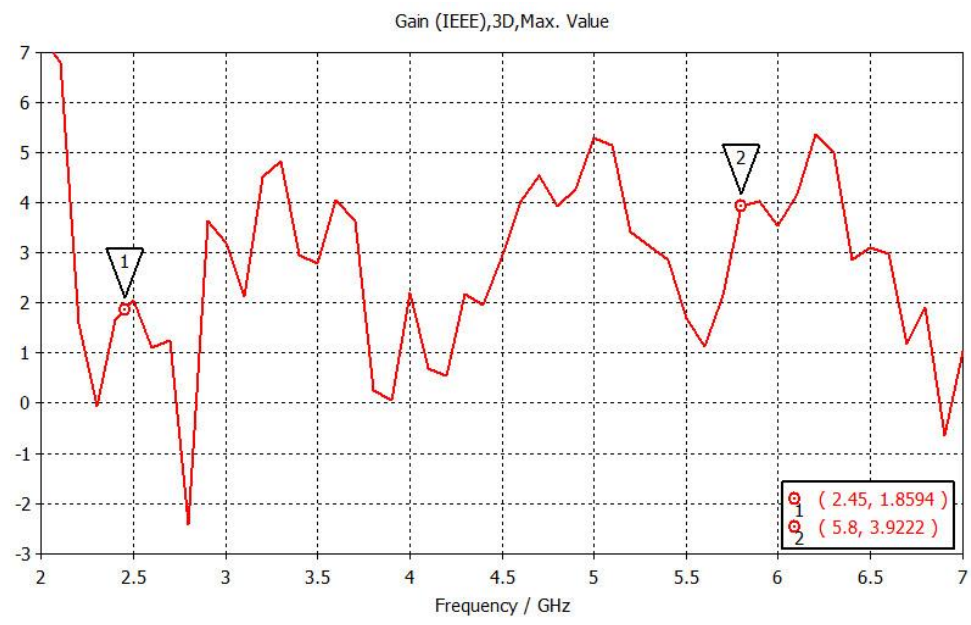

Figure 10. Gain vs. frequency of the proposed antenna 

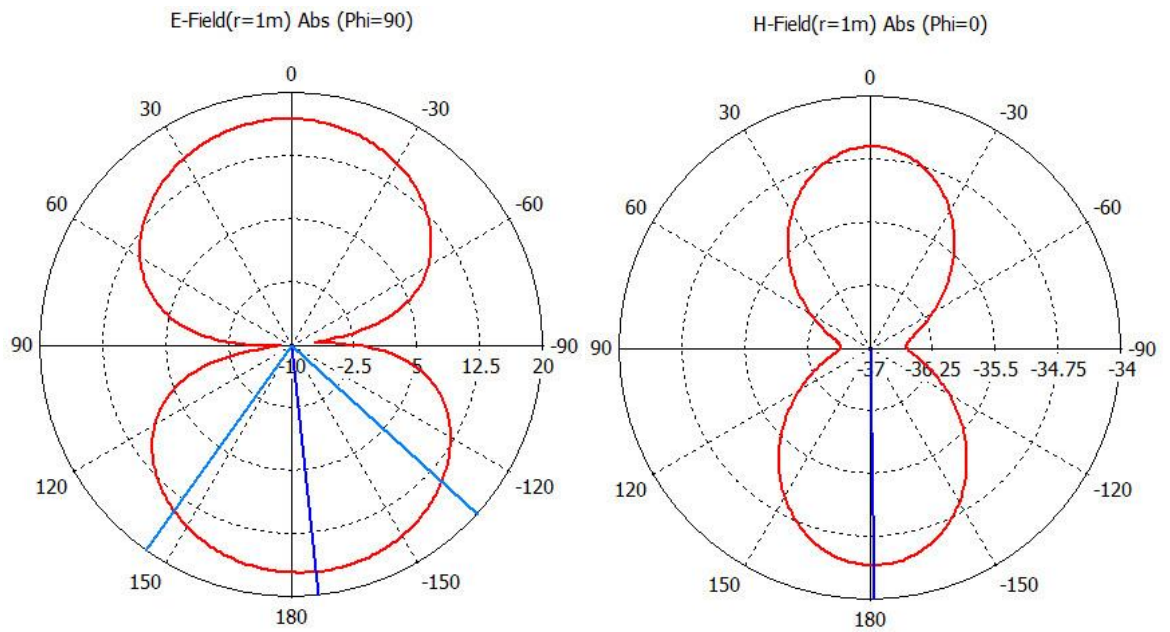

Figure 11. Radiation pattern of the proposed antenna at $2.45 \mathrm{GHz}$, (a) E-plane, (b) H-plane
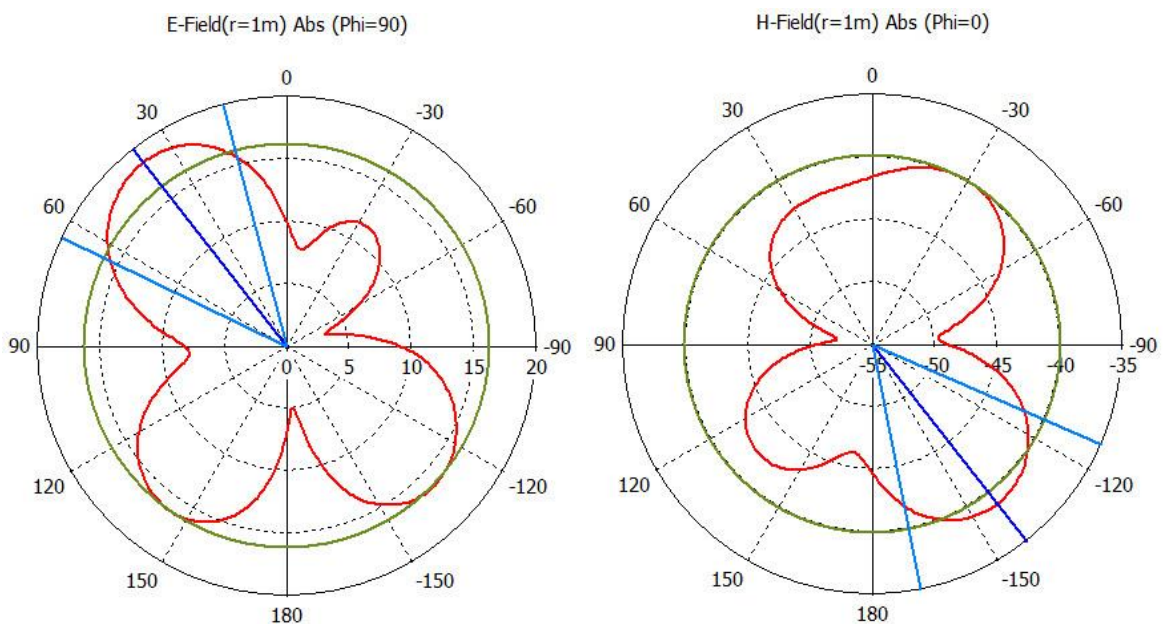

Figure 12. Radiation pattern of the proposed antenna at $5.8 \mathrm{GHz}$, (a) E-plane, (b) H-plane

Figure 13 illustrates the surface current distributions of the proposed antenna at $2.45 \mathrm{GHz}$ and 5.8 GHz. As observed in the figure, the current is concentrated around the L-shaped slot and around the complementary split ring resonators for both frequencies.

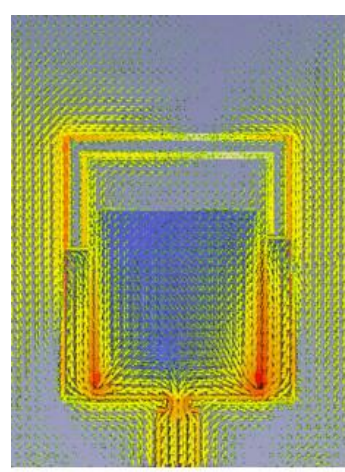

a

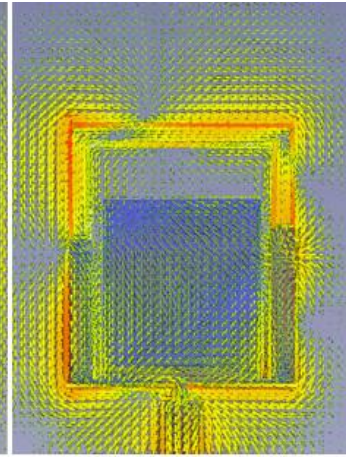

b

Figure 13. Surface current distributions of the proposed antenna at, (a) $2.45 \mathrm{GHz}$, (b) $5.8 \mathrm{GHz}$ 


\section{ACHIEVEMENT AND MEASUREMENT RESULTS}

After validation of the simulation results of the proposed antenna using CST and HFSS, a prototype of the final optimized circuit was fabricated using LPKF machine. The proposed antenna is manufactured on the FR-4 substrate with a thickness of $1.6 \mathrm{~mm}$ and dielectric constant of 4.4. Figure 14 shows a photograph of the manufactured antenna. As can observed, this antenna is simple in fabrication, has a single layer and a total size of $30 \mathrm{~mm} \times 40 \mathrm{~mm}$.

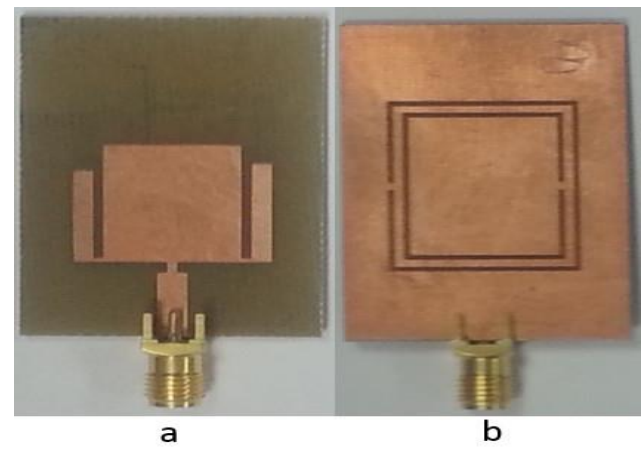

Figure 14. Photograph of the manufactured antenna

The experimental results of the manufactured antenna are measured by using a Vector Network Analyzer from Rohde \& Schwarz. The comparison of the simulated and the measured results of S-parameters are presented in Figure 15. As seen in the figure, the measured results have a good agreement with the simulated results.

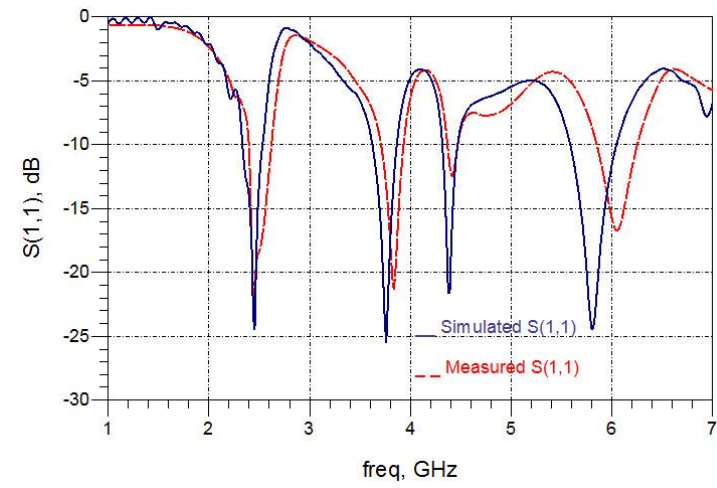

Figure 15. Comparison of simulated and measured return loss

Table 2 presents a summary of the performance of the proposed antenna at the RFID frequency bands $2.45 \mathrm{GHz}$ and $5.8 \mathrm{GHz}$. From this comparison, we can notice that the measured impedance bandwidth is higher than the simulated results by a $30 \mathrm{MHz}$ at first RFID band and $217 \mathrm{MHz}$ at the second RFID band.

Table 2. Comparison between measurement and simulation results

\begin{tabular}{cccc}
\hline & $\begin{array}{c}\text { Resonance frequency } \\
(\mathrm{GHz})\end{array}$ & $\begin{array}{c}\text { Return loss } \\
(\mathrm{dB})\end{array}$ & $\begin{array}{c}\text { Bandwidth } \\
(\mathrm{MHz})\end{array}$ \\
\hline Simulation & 2.45 & -25 & 190 \\
CST & 5.8 & -24 & 458 \\
Simulation & 2.45 & -16.84 & 150 \\
HFSS & 5.8 & -22.5 & 360 \\
Measurement & 2.45 & -21.07 & 210 \\
& 5.8 & -20.86 & 675 \\
\hline
\end{tabular}


The proposed antenna performances were compared to some existing work in the literature in term of total area occupied by the antenna, the comparison results are presented in Table 3, we can conclude that the proposed antenna has a miniaturized size.

Table 3. Comparison of proposed antenna performance with some existing antennas

\begin{tabular}{ccccc}
\hline Ref. & $\begin{array}{c}\text { Dimensions } \\
(\mathrm{mm} 2)\end{array}$ & $\begin{array}{c}\text { Total area } \\
(\mathrm{mm} 2)\end{array}$ & $\begin{array}{c}\text { Resonance } \\
\text { frequency } \\
(\mathrm{GHz})\end{array}$ & $\begin{array}{c}\text { Antenna } \\
\text { purpose }\end{array}$ \\
\hline$[13]$ & $60 \times 80$ & 4800 & 2.45 & Monoband \\
{$[14]$} & $60 \times 60$ & 3600 & $2.45 / 5.8$ & Dual band \\
{$[15]$} & $75 \times 75$ & 5625 & $2.4 / 5$ & Dual band \\
{$[16]$} & $50 \times 35$ & 1750 & $2.4 / 5.8$ & Dual band \\
Proposed antenna & $40 \times 30$ & 1200 & $2.45 / 5.8$ & Dual band \\
\hline
\end{tabular}

\section{CONCLUSION}

In this paper, we present a new dual band printed antenna for RFID applications based on metamaterial, which operates at two RFID band $2.45 \mathrm{GHz}$ and $5.8 \mathrm{GHz}$. The effect of the complementary split ring resonator on the antenna performances was investigated. The proposed antenna presents good results in terms of bandwidth, return loss and gain, these results are due to the integration of the CSRR structure in the ground plane. The proposed antenna was simulated and validated by using two electromagnetic solver CST and HFSS. The manufactured antenna was measured using a VNA and the measured results are in good agreement with the simulated one.

\section{REFERENCES}

[1] Ennajih A, Zbitou J, Errkik A, Tajmouati A, El Abdellaoui L, Latrach M. A novel design of passive UHF RFID tag antenna mounted on paper. 2017 IEEE International Conference on Wireless Technologies, Embedded and Intelligent Systems (WITS), Fez, Morocco. 2017; 1-6.

[2] Chaouki G, Abdelhak F, Ali G. A Modified Fractal Bow Tie Antenna for an RFID Reader. International Journal of Electrical and Computer Engineering (IJECE). 2014; 4(3): 441-446.

[3] Evizal, Tharek A, Sharul KA, Sri L R.Development of RFID EPC Gen2 Tag for Multi Access Control System. International Journal of Electrical and Computer Engineering (IJECE).2013; 3(6): 724-731.

[4] Ennajih A, Zbitou J, Latrach M, Errkik A, El Abdellaoui L, Tajmouati A. Dual Band Metamaterial Printed Antenna Based on CSRR For RFID Applications. International Journal of Microwave and Optical Technology.2017; 12(2): 106-113.

[5] Sofi A, Roky K, Bouhorma M, Baraka IH.Novel Antennas for UHF RFID Tags: Design and Miniaturization. International Journal of Electrical and Computer Engineering (IJECE).2014; 4(1): 75-80.

[6] Choi J, Kim U, Kim T. Design of RFID reader antennas for UHF RFID handheld systems. 2011 proc. International Workshop on Antenna Technology (iWAT). 2011; 33-36.

[7] Veselago VG. The electrodynamics of substances with simultaneously negative values of $\varepsilon$ and $\mu$. Physics-Uspekhi. 1968; 10(4): 509-514.

[8] Marques R, Mesa F, Martel J, Medina F. Comparative analysis of edge- and broadside-coupled split ring resonators for metamaterial design - Theory and experiments. IEEE Transactions on Antennas and Propagation. 2003; 51(10): $2572-2581$.

[9] Marqués R, Medina F, Rafii ER. Role of bianisotropy in negative permeability and left-handed metamaterials. Physical Review B.2002; 65(14): 144440.

[10] Durán-Sindreu M, Naqui J, Paredes F, Bonache J, Martín F. Electrically Small Resonators for Planar Metamaterial Microwave Circuit and Antenna Design: A Comparative Analysis. Applied Sciences.2012; 2(4): 375-395.

[11] Karimzadeh BK, Dadashzadeh G, Kharakhili FG. Using of CSRR and its Equivalent Circuit Model in Size Reduction of Microstrip Antenna.2007 proc. Asia-Pacific Microwave Conference. 2007; 1-4.

[12] Yeoman MS, O 'neill MA. Impedance Matching of Tag Antenna to Maximize RFID Read Ranges ; Design Optimization. 2014 proc. COMSOL Conference. 2014.

[13] Al-Shaheen A,. New Patch Antenna for Ism Band At 2.45 Ghz. ARPN Journal of Engineering and Applied Sciences. 2012; 7(1): 1-9.

[14] Rani MSA, Rahim SKA, Tharek AR, Peter T, Cheung SW. Dual-band Transparent Antenna for ISM Band Applications.2013 proc. Progress in Electromagnetics Research Symposium, Taipei.2013; 490-493.

[15] Wu JW. 2.4/5-GHz dual-band triangular slot antenna with compact operation. Microwave and Optical Technology Letters. 2005; 45(1): 81-84.

[16] Panda JR, Kshetrimayum RS. A Printed 2.4 Ghz/5.8 Ghz Dual-Band Monopole Antenna with A Protruding Stub in The Ground Plane for Wlan And Rfid Applications. Progress In Electromagnetics Research. 2011; 117: 425-434. 